\title{
3D Face Scanner Comparison: Visual and Anthropometric Accuracy Analysis
}

\author{
Minji YU, Alison CLOET, Linsey A. GRIFFIN \\ University of Minnesota, St. Paul, (MN), USA \\ https://doi.org/10.15221/21.41
}

\begin{abstract}
Compared to traditional manual measurement methods, 3D face scanning has opened more design possibilities for face protection product development, such as masks and goggles, by acquiring the three-dimensional shape and dimension. Various scanning technologies have been developed with different levels of price, expertise, and functional sophistication. In order to appropriately utilize 3D face scan data for a particular purpose, it is crucial to understand the characteristics of each scanner and validate their accuracy. The purpose of this study was to compare the visual and anthropometric accuracy of 3D face scanners and explore the characteristics and applicability of each scanner. Threedimensional face data of nine participants were acquired with three scanners: Artec Leo, Structure Sensor, and Bellus3D FaceApp. Before scanning, seven landmarks were marked, and five measurements were taken manually. The visual accuracy of each scanner was evaluated by experts through a survey with real-time comparison between scan and real face. It included assessment for distortion of textured and non-textured scans, as well as the visibility of landmarks. Measurements were obtained using Rhino 7 and Anthroscan ScanWorX software, and the anthropometric accuracy of each scanner was compared based on the manual measurements. The results of this study presented the visual and dimensional accuracy of the face mesh creation of three scanners, providing a comprehensive review of possible uses in consideration of the cost and usability of each scanner.
\end{abstract}

Keywords: 3d face scanning, face anthropometry, visual accuracy

\section{Introduction}

Dimensional information of the face area is worthwhile in product development. Analysis of the face region is important in designing a basic framework for better fit and evaluation throughout the development of wearable products worn on the face $[1,2,3]$. Utilizing 3D scans can be used to achieve a better fit for everyone or a customized fit for a specific target population. Fit and comfort are critical in medical and protective products such as a mask or goggles to achieve their functional and protective purpose $[4,5,6]$.

In the past, two-dimensional methods such as measurements with calipers and photographic images were mainly used to acquire dimensional information of a face. However, these methods are difficult to understand the three-dimensional shape of a face because it is only possible to obtain information about the measurements and analyze the face shape in a linear, flat manner. On the other hand, the introduction of 3D scanning technology enables a broader and more comprehensive understanding of a face shape by obtaining three-dimensional mesh $[7,8,9]$. In addition, it opens up further possibilities, such as the development of wearable products with better fit using 3D modeling or reverse engineering $[10,11]$. Compared to manual measurement, 3D face anthropometry has the advantage of being able to measure repeatedly for high data reliability and to get additional measurement data that was not initially acquired later if necessary [12].

Despite the advantages of 3D face scanning, validation and comparison of different types of these technologies have not been adequately studied. In order to utilize 3D face scan data, it is essential to verify the accuracy of the acquired 3D scan data $[13,14]$. Since the base method and sophistication of each 3D face scanning technology are diverse, comprehensive evaluation and validation in various aspects such as dimensional and visual accuracy are required [15,16,17].

The purpose of this study was to explore the characteristics and applicability of various 3D face scanning technologies. Three 3D face scanners with different cost levels and types were evaluated for visual and anthropometric accuracy. The usefulness of each face scanning technology was investigated based on its features and level of sophistication. 


\section{Methods}

\subsection{Overview and Preparation}

In order to compare the attributes and operating procedures of face scanning technologies, three scanners with various cost and expertise levels were selected for this study: Artec Leo (Artec 3D, Luxembourg, Luxembourg), Structure Sensor (ST01, Occipital, Inc., San Francisco, CA, USA), and Bellus3D FaceApp (Version 1.9.7.21 P, Bellus3D, Inc., Campbell, CA, USA). The detailed specifications of each scanner are summarized in Table 1. Scanners were assessed integrally through visual and anthropometric accuracy evaluation.

Table 1. Comparison of specifications for scanners

\begin{tabular}{|c|c|c|c|}
\hline & Artec Leo & Structure Sensor & Bellus3D FaceApp \\
\hline List Price & $\$ 29,800$ & $\begin{array}{c}\$ 527 \sim 715 \\
\text { (varies with bundle) }\end{array}$ & $\begin{array}{c}\text { Free } \\
(\$ 0.99 \text { per } 1 \text { data exportation })\end{array}$ \\
\hline Installation & Handheld device & iPad mounted & IOS application \\
\hline Face Scanning Time & 30 to 60 seconds & 60 to 180 seconds & 30 seconds \\
\hline Post-processing & $\begin{array}{c}\text { Autopilot } \\
\text { with Artec Studio software }\end{array}$ & $\begin{array}{l}\text { Automatically generated } \\
\text { after scanning }\end{array}$ & $\begin{array}{c}\text { Automatically generated } \\
\text { after scanning }\end{array}$ \\
\hline Claims of Precision & up to $0.1 \mathrm{~mm}$ & $\begin{array}{c}0.5 \mathrm{~mm} \text { at } 40 \mathrm{~cm} \\
30 \mathrm{~mm} \text { at } 3 \mathrm{~m}\end{array}$ & Not listed \\
\hline
\end{tabular}

Participants were University of Minnesota faculty and students, who were recruited as a convenience sampling due to recruitment limits imposed by Covid-19. They consisted of 7 Caucasians and 2 Asians, of which 5 were female and 4 were male.

In order to maintain scan quality and obtain an accurate head shape, participants were asked to wear a wig cap. Seven landmarks, defined by the International Organization for Standardization, were marked on the participant's face with a circle of $2 \mathrm{~mm}$ diameter using a green washable marker. A total of five manual measurements were taken using a small bone caliper (Model 01294, Lafayette Instrument, Lafayette, IN, USA) and a digital caliper (Adoric, Orlando, FL, USA): M1 (head frontal width; tragion-tragion), M2 (head lateral width; sellion to back head), M3 (nose length; sellion to pronasale), M4 (full-face length; sellion to menton), M5 (half-face length; pronasale to menton). Manual measuring was performed by the researcher who obtained discrepancies of less than $1 \mathrm{~mm}$ by repeating the face length and width measurements 10 times through the pre-test. The maximum allowable error for the head area is $1 \mathrm{~mm}$ according to ISO [18], and the standard deviation of the researcher's repeated measurements of the face was $0.59 \mathrm{~mm}$.

3D face scanning was performed with the participant sitting on an installed chair, facing the front, and with eyes closed. To avoid possible data and mapping errors, the face was scanned twice for each scanner and the data was checked for any abnormalities by the researcher.

\subsection{Visual Accuracy Evaluation}

The visual accuracy of face scans was assessed by three experts using a survey of one selected participant. Expert selection criteria were those who have received graduate-level education in apparel studies major and have experience with 3D scanning and data processing. The 3D faces obtained with the three scanners were extracted in two versions, a textured and a non-textured model; A total of six scan data were evaluated. The textured models were mapped with the participant's facial pictures, while the untextured models were a single color which was advantageous to see the contour of the 3D mesh.

The survey was created through the Qualtrics website, and the questions with a 5-point Likert scale consisted of items to evaluate the visual accuracy of 3D face models in various aspects: sharpness, similarity, distortion, and landmark visibility. The landmark visibility question was excluded for the nontextured models because landmarks were color-coded with the marker. In order to increase the reliability of the evaluation results, definitions of terms for the questions and sample images to understand the anchor level were provided. Experts conducted visual accuracy evaluation in the Human Dimensioning Lab of the University of Minnesota. Dual monitors were set: monitor 1 for a survey and monitor 2 for interacting with the six 3D face models in Meshmixer 3.5 (Autodesk, Inc., San Rafael, CA, USA). The participant was seated 6 feet apart so that the experts could refer to the participant's real face and compare it with 3D models in real-time through the entire survey. All scan data with and without 
texture were provided separately and the order was randomized to prevent the experts from evaluating them in conjunction. Completed responses were analyzed with descriptive statistics using SPSS 26.0 for Windows.

\subsection{Anthropometric Accuracy Evaluation}

For anthropometric accuracy evaluation of face scans from the three scanners, the dimensions of nine participants' 3D face models were measured and compared with manual measurements. Since the 3D models by the Structure Sensor were 1/1000 of the actual size, they were measured after editing to the actual size using Meshmixer. All 3D models in OBJ format were imported into Rhino 7 (Robert McNeel and Associates, Seattle, WA, USA) for measurement. The measuring process was performed from various angles with the quadrant screen of perspective, top, front, and right view. The display mode was set to 'rendered' to refer to the texture of the 3D models. To create a landmark for 3D anthropometry, the 'SnapToMeshObject' command was executed so that the point was located only on the surface of a 3D model. Then, using the 'Single Point' command, points were created at the location of the landmarks. Afterward, using the 'Linear dimension' and 'Aligned dimension' measurement tools, five measurements corresponding to the manual measurements with calipers were measured. M2 (head lateral width) was measured from the side view after creating a point on the back of the head in a horizontal position with the sellion as in the manual measurement method. Throughout the measurement process, the 'Point Object Snap' of the 'Osnap' option was turned on so that the correct landmark point could be selected. All 3D models were double-checked to ensure they were measured correctly by measuring once more with Anthroscan ScanWorX software (Human Solutions GmbH, Heidelberg, Germany).

\section{Results}

\subsection{Visual Accuracy Comparison}

Table 2 presents images of textured and non-textured models acquired with Artec Leo, Structure Sensor, and Bellus3D FaceApp. Table 3 shows the results of a visual accuracy evaluation for six models.

Sharpness was a measure of whether a 3D model was sharp and clear enough to detect the participant's actual face shape. The detailed areas of the face were evaluated separately: nose, chin, ears, and overall face. The definition of sharpness was presented as 'the curves and edges of the 3D mesh are sharp to detect the details of the original appearance.' Overall, Artec Leo received high sharpness scores over 4.67 with excellent visual clarity and the non-textured model had the highest score in most of the face areas. It was judged that Artec Leo was able to implement even small details well by obtaining the highest score for the ear part, which has a complex shape among the face. The textured model of Bellus3D FaceApp had high sharpness with a score of 4.50 , but the score of the nontextured model was relatively low at 2.83. This result was judged to be because Bellus3D FaceApp is a photogrammetry-based technology that captures the participant's face with clear, high-resolution textures. For this reason, the textured scan looked clear, but the 3D mesh shape viewed with the nontextured model was not as clear as the participant's face contour. The non-textured model of Bellus3D FaceApp had noticeably low sharpness of the ears, which may be attributed to the fact that the ear areas were too lumpy to clearly see the outlines of the ears. The textured model of Structure Sensor had the lowest sharpness among the three scanners with an average score of 2.00. The non-textured model was relatively higher than the textured model but still had a low score of 3.00 . Detailed areas such as the nose and ears had particularly lower sharpness scores than wider areas.

Similarity was a measure of how similar the scan data was to the actual face of the participant. Artec Leo showed a high degree of similarity to the participant's real face as a whole with an average of 4.67, and the non-textured model had the highest score of 4.83 . The textured model of Bellus 3D still had a relatively high level of similarity with a score of 3.67 , but the non-textured model received a low overall average of 2.83. The ear of the non-textured model scored only 1.67 , which was lower than other areas. The Structure Sensor received the lower similarity score among the three scanners overall, and the similarity of nose and ears tended to decrease. The textured model with Structure Sensor was the lowest with an average of 1.75 , which is thought to be because the participant's face shape was distorted due to a texture mapping error. 
Proceedings of 3DBODY.TECH 2021

12th Int. Conference and Exhibition on 3D Body Scanning and Processing Technologies, 19-20 Oct. 2021, Lugano, Switzerland

Table 2. 3D face model Images

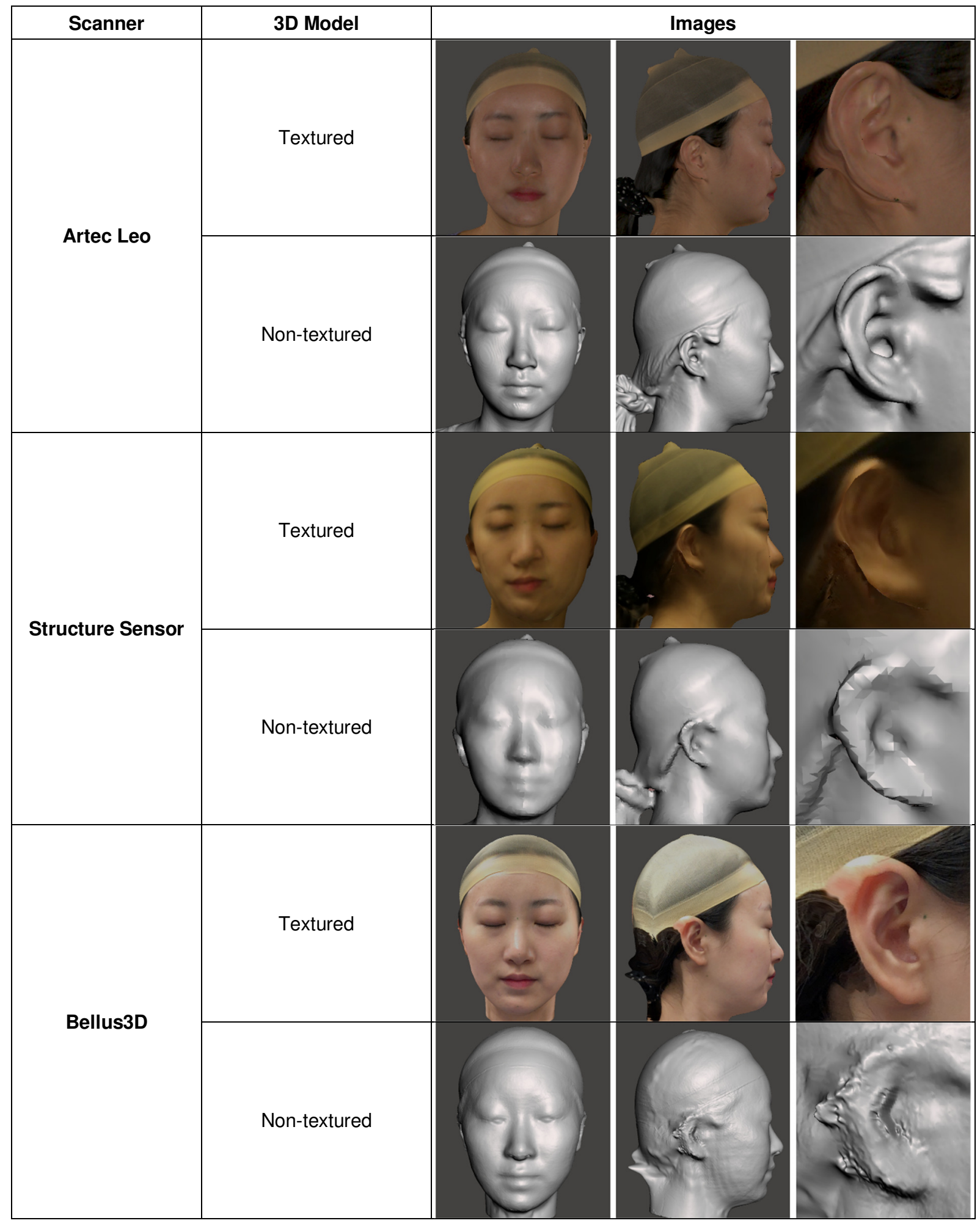


Table 3. Visual Accuracy Evaluation Results

\begin{tabular}{|c|c|c|c|c|c|c|c|}
\hline & \multicolumn{3}{|c|}{ Textured } & \multicolumn{3}{|c|}{ Non-textured } \\
\hline & & Artec Leo & Structure & Bellus3D & Artec Leo & Structure & Bellus3D \\
\hline \multirow{5}{*}{$\begin{array}{c}\text { Sharpness } \\
\text { (1: Not sharp/clear } \\
\text { at all; } \\
\text { 5: Very sharp/clear) }\end{array}$} & Nose & 4.33 & 1.67 & 4.67 & 5.00 & 3.00 & 3.33 \\
\hline & Chin & 4.67 & 2.33 & 5.00 & 5.00 & 3.67 & 3.33 \\
\hline & Ears & 5.00 & 1.67 & 3.67 & 5.00 & 2.00 & 1.00 \\
\hline & Overall Face & 4.67 & 2.33 & 4.67 & 4.67 & 3.33 & 3.67 \\
\hline & Mean & 4.67 & 2.00 & 4.50 & 4.92 & 3.00 & 2.83 \\
\hline \multirow{5}{*}{$\begin{array}{c}\text { Similarity } \\
\text { (1: Not similar at all; } \\
\text { 5: Very similar) }\end{array}$} & Nose & 4.67 & 1.00 & 3.67 & 4.67 & 3.33 & 2.67 \\
\hline & Chin & 4.67 & 2.67 & 4.00 & 5.00 & 3.67 & 3.33 \\
\hline & Ears & 4.67 & 1.67 & 3.33 & 4.67 & 2.67 & 1.67 \\
\hline & Overall Face & 4.67 & 1.67 & 3.67 & 5.00 & 3.33 & 3.67 \\
\hline & Mean & 4.67 & 1.75 & 3.67 & 4.83 & 3.25 & 2.83 \\
\hline \multirow{5}{*}{$\begin{array}{c}\text { Distortion } \\
\text { (1: Very distorted; } \\
\text { 5: Not distorted at all) }\end{array}$} & Nose & 5.00 & 1.33 & 4.67 & 4.67 & 3.67 & 3.33 \\
\hline & Chin & 4.67 & 3.00 & 4.67 & 5.00 & 4.00 & 3.67 \\
\hline & Ears & 4.67 & 2.33 & 4.00 & 4.67 & 3.00 & 1.67 \\
\hline & Overall Face & 4.67 & 2.00 & 4.33 & 5.00 & 4.00 & 3.67 \\
\hline & Mean & 4.75 & 2.17 & 4.42 & 4.83 & 3.67 & 3.08 \\
\hline $\begin{array}{l}\text { Landmark Visibility } \\
\text { (1: None of landmarks } \\
\text { are visible; } \\
\text { 5: All } 7 \text { landmarks } \\
\text { are visible) }\end{array}$ & Overall Face & 5.00 & 2.00 & 5.00 & $\mathrm{~N} / \mathrm{A}$ & $\mathrm{N} / \mathrm{A}$ & $\mathrm{N} / \mathrm{A}$ \\
\hline
\end{tabular}

Distortion was a measure of how distorted this 3D model was from the real face, and the presented definition of distortion was 'the changing of the appearance in a way that makes it seem strange or unclear.' Artec Leo's textured and non-textured models obtained average scores of 4.75 and 4.83 , respectively, and were judged to acquire the participant's appearance well with little distortion. Bellus3D FaceApp's textured model also showed a high overall average of 4.42. However, Bellus3D FaceApp's non-textured model obtained a relatively low score with an average of 3.08. In particular, the score for the ear area was the lowest among the six scans with a score of 1.67, indicating severe distortion. The non-textured model of the Structure Sensor had an average of 3.67, which was lower than that of Artec Leo, but not severe. The textured model of Structure Sensor showed more severe distortion than other scanners with an average of 2.17 , and the score of the nose area was particularly distorted with a score of 1.33 .

For textured models, landmark visibility was reviewed. It was a quantitative evaluation method of how many landmarks were visible and clearly identifiable without distortion in a total of 7 landmarks marked with a $2 \mathrm{~mm}$ diameter circle on the participant's skin. For Artec Leo and Bellus3D FaceApp, all three experts evaluated that all 7 landmarks were visible, which would be advantageous when measuring the face dimensions of the 3D model. Structure Sensor had an average landmark visibility score of 2.00 which means that only 1-2 landmarks were visible, so it was difficult to accurately specify the location of the landmark.

To summarize, Artec Leo obtained the highest overall visual accuracy score in both textured and nontextured models. It was confirmed that Artec Leo acquired the participant's face similarly and clearly without distortion, even in the detailed areas such as the nose and ears. Bellus3D FaceApp obtained a good overall score for the textured model, but it might be because it was based on photogrammetry that maps pictures into 3D form. The non-textured model, in which experts could easily observe 3D mesh shape, had low visual accuracy, so it is hard to say that Bellus3D FaceApp acquired the accurate shape. 
Therefore, Bellus3D FaceApp can be used for design or exhibiting purposes that do not require 3D mesh shape accuracy. Structure Sensor had an error in texture mapping depending on the scanning environment. For this reason, the mesh shape was perceived as visually distorted and dissimilar when textured, even though the non-textured model had moderate sharpness and similarity. Structure Sensor has the possibility of using non-textured scans for purposes other than visual display, but it is judged that the usefulness of textured scans would be low.

\subsection{Anthropometric Accuracy Comparison}

Table 4 shows the differences between the dimensions of the three scanners' $3 \mathrm{D}$ models and the manual measurements. Discrepancies with manual measurements for each participant were recorded and differences were averaged as absolute values with standard deviations. The anthropometric accuracy of each scanner was analyzed based on the ISO standard which states that the allowable error range for face and head scanning is $\pm 1 \mathrm{~mm}$.

Artec Leo showed differences and standard deviations of less than $1 \mathrm{~mm}$ in most of the five measurements, showing little variation between participants and consistently high dimensional accuracy. M3 (nose length), one of the important dimensions in the development of products worn on the face, had an average mean absolute difference of $0.67 \mathrm{~mm}$ with manual measurement. The mean absolute differences of M2 (head lateral width) and M4 (full-face length) were 0.44 and $0.56 \mathrm{~mm}$, respectively, indicating that Artec Leo's anthropometric accuracy for face width and length was high. M1 (head frontal width), which was relatively different from the manual measurement, also showed a difference close to $1 \mathrm{~mm}$ with an average of $1.11 \mathrm{~mm}$.

Structure Sensor had lower accuracy than Artec Leo with a mean absolute difference range of 0.56 to $1.89 \mathrm{~mm}$, but still close to the allowable error range. M5 (half-face length) difference was $0.67 \mathrm{~mm}$, which was even more accurate than Artec Leo's average of $0.89 \mathrm{~mm}$. The mean absolute difference of M3 (nose length) was $0.78 \mathrm{~mm}$. However, for dimensions of relatively large areas, the average absolute difference increased to more than $1 \mathrm{~mm}$, resulting in a slightly decreased accuracy. In particular, M1 (head frontal width) had a mean absolute difference of $1.89 \mathrm{~mm}$ and a standard deviation of $1.76 \mathrm{~mm}$, showing a rather large variation between participants and relatively poor accuracy. In the four items except for $\mathrm{M} 1$, the standard deviation ranged from 0.67 to $1.20 \mathrm{~mm}$, indicating that the absolute dimensional difference between participants was not large with somewhat consistently high dimensional accuracy.

Bellus3D FaceApp showed a wide distribution of mean absolute differences. M3 (nose length) showed a mean absolute difference of $1 \mathrm{~mm}$. Except for this, the other four dimensions had differences from 1 to $5.44 \mathrm{~mm}$, resulting in low dimensional accuracy. The reason for the high accuracy of the nose area was considered as follows: 1) the nose area is relatively narrow so the dimensional error range could be small, and 2) the nose is fully captured at the beginning of scanning with Bellus 3D. Bellus3D showed an average difference of $5.44 \mathrm{~mm}$ and a standard deviation of $0.88 \mathrm{~mm}$ in $\mathrm{M} 1$ (head frontal width), and it was consistently 4 to $6 \mathrm{~mm}$ larger for all participants. In addition, M2 (head lateral width) had an average absolute difference of $4.44 \mathrm{~mm}$ and a standard deviation of $2.01 \mathrm{~mm}$. The differences were inconsistently distributed from -2 to $+6 \mathrm{~mm}$ for participants, so it was not possible to specify the tendency and the dimensional reliability was low. M4 (full-face length) had an average absolute difference of $1.56 \mathrm{~mm}$ on average and M5 (half-face length) had $2.22 \mathrm{~mm}$, which was higher than the horizontal dimension of the face, but still showed the lowest accuracy among the three scanners.

In summary, Artec Leo had high anthropometric accuracy with an allowable level of dimensional difference overall and even in small areas of the face. On the other hand, Bellus3D FaceApp showed the largest difference from manual measurement and had a wide deviation range between participants, resulting in low dimensional accuracy and low reliability. Bellus3D FaceApp's accuracy was particularly poor in dimensions measuring the width of the face, which is thought to be due to the process that participants should rotate their faces in various directions during the scanning. Structure Sensor had lower accuracy than Artec Leo but showed a difference within $2 \mathrm{~mm}$ in all dimension items. Therefore, Structure Sensor had somewhat higher accuracy with a consistent error rate in measuring the widths and lengths of the face. 
Table 4. Face measurements compared to manual measurement

\begin{tabular}{|c|c|c|c|c|c|c|c|c|c|c|c|}
\hline & & \multicolumn{9}{|c|}{$\begin{array}{c}\text { Value } \\
\text { (Difference with manual measurement) }\end{array}$} & \multirow{2}{*}{$\begin{array}{l}\text { Mean absolute } \\
\text { difference } \\
\text { with manual } \\
\text { measurement } \\
\text { (S.D.) }\end{array}$} \\
\hline & & $\mathrm{P} 1$ & P2 & P3 & P4 & P5 & P6 & P7 & P8 & P9 & \\
\hline \multirow{4}{*}{$\begin{array}{c}\text { M1. } \\
\text { Head } \\
\text { Frontal } \\
\text { Width }\end{array}$} & Manual & 143 & 132 & 137 & 145 & 145 & 139 & 153 & 150 & 150 & \\
\hline & Artec Leo & $\begin{array}{l}144 \\
(+1)\end{array}$ & $\begin{array}{c}132 \\
(0)\end{array}$ & $\begin{array}{l}137 \\
(0)\end{array}$ & $\begin{array}{l}147 \\
(+2)\end{array}$ & $\begin{array}{l}147 \\
(+2)\end{array}$ & $\begin{array}{l}139 \\
(0)\end{array}$ & $\begin{array}{l}155 \\
(+2)\end{array}$ & $\begin{array}{l}151 \\
(+1)\end{array}$ & $\begin{array}{l}152 \\
(+2)\end{array}$ & $\begin{array}{c}1.11 \\
(0.93)\end{array}$ \\
\hline & Structure & $\begin{array}{l}146 \\
(+3)\end{array}$ & $\begin{array}{c}132 \\
(0)\end{array}$ & $\begin{array}{l}141 \\
(+4)\end{array}$ & $\begin{array}{l}150 \\
(+5)\end{array}$ & $\begin{array}{l}146 \\
(+1)\end{array}$ & $\begin{array}{l}138 \\
(-1)\end{array}$ & $\begin{array}{l}153 \\
(0)\end{array}$ & $\begin{array}{l}151 \\
(+1)\end{array}$ & $\begin{array}{l}152 \\
(+2)\end{array}$ & $\begin{array}{c}1.89 \\
(1.76)\end{array}$ \\
\hline & Bellus 3D & $\begin{array}{l}147 \\
(+4)\end{array}$ & $\begin{array}{l}138 \\
(+6)\end{array}$ & $\begin{array}{l}141 \\
(+4)\end{array}$ & $\begin{array}{l}151 \\
(+6)\end{array}$ & $\begin{array}{l}151 \\
(+6)\end{array}$ & $\begin{array}{l}145 \\
(+6)\end{array}$ & $\begin{array}{l}159 \\
(+6)\end{array}$ & $\begin{array}{l}156 \\
(+6)\end{array}$ & $\begin{array}{l}155 \\
(+5)\end{array}$ & $\begin{array}{c}5.44 \\
(0.88)\end{array}$ \\
\hline \multirow{4}{*}{$\begin{array}{l}\text { M2. } \\
\text { Head } \\
\text { Lateral } \\
\text { Width }\end{array}$} & Manual & 179 & 201 & 190 & 193 & 204 & 195 & 191 & 206 & 202 & \\
\hline & Artec Leo & $\begin{array}{l}180 \\
(+1)\end{array}$ & $\begin{array}{c}201 \\
(0)\end{array}$ & $\begin{array}{c}190 \\
(0)\end{array}$ & $\begin{array}{l}192 \\
(-1)\end{array}$ & $\begin{array}{l}205 \\
(+1)\end{array}$ & $\begin{array}{c}195 \\
(0)\end{array}$ & $\begin{array}{l}191 \\
(0)\end{array}$ & $\begin{array}{c}206 \\
(0)\end{array}$ & $\begin{array}{l}203 \\
(+1)\end{array}$ & $\begin{array}{c}0.44 \\
(0.53)\end{array}$ \\
\hline & Structure & $\begin{array}{l}180 \\
(+1)\end{array}$ & $\begin{array}{l}202 \\
(+1)\end{array}$ & $\begin{array}{l}194 \\
(+4)\end{array}$ & $\begin{array}{c}193 \\
(0)\end{array}$ & $\begin{array}{l}206 \\
(+2)\end{array}$ & $\begin{array}{l}194 \\
(-1)\end{array}$ & $\begin{array}{l}190 \\
(-1)\end{array}$ & $\begin{array}{c}206 \\
(0)\end{array}$ & $\begin{array}{l}203 \\
(+1)\end{array}$ & $\begin{array}{c}1.22 \\
(1.20)\end{array}$ \\
\hline & Bellus 3D & $\begin{array}{l}183 \\
(+4)\end{array}$ & $\begin{array}{l}198 \\
(-3)\end{array}$ & $\begin{array}{l}196 \\
(+6)\end{array}$ & $\begin{array}{l}198 \\
(+5)\end{array}$ & $\begin{array}{l}200 \\
(-4)\end{array}$ & $\begin{array}{l}193 \\
(-2)\end{array}$ & $\begin{array}{l}199 \\
(+8)\end{array}$ & $\begin{array}{l}204 \\
(-2)\end{array}$ & $\begin{array}{l}208 \\
(+6)\end{array}$ & $\begin{array}{c}4.44 \\
(2.01)\end{array}$ \\
\hline \multirow{4}{*}{$\begin{array}{c}\text { M3. } \\
\text { Nose } \\
\text { Length }\end{array}$} & Manual & 44 & 50 & 46 & 50 & 51 & 46 & 52 & 54 & 47 & \\
\hline & Artec Leo & $\begin{array}{c}45 \\
(+1)\end{array}$ & $\begin{array}{c}49 \\
(-1)\end{array}$ & $\begin{array}{l}46 \\
(0)\end{array}$ & $\begin{array}{c}51 \\
(+1)\end{array}$ & $\begin{array}{l}51 \\
(0)\end{array}$ & $\begin{array}{c}47 \\
(+1)\end{array}$ & $\begin{array}{c}51 \\
(-1)\end{array}$ & $\begin{array}{c}53 \\
(-1)\end{array}$ & $\begin{array}{l}47 \\
(0)\end{array}$ & $\begin{array}{c}0.67 \\
(0.50)\end{array}$ \\
\hline & Structure & $\begin{array}{c}45 \\
(+1)\end{array}$ & $\begin{array}{c}48 \\
(-2)\end{array}$ & $\begin{array}{l}46 \\
(0)\end{array}$ & $\begin{array}{c}51 \\
(+1)\end{array}$ & $\begin{array}{c}50 \\
(-1)\end{array}$ & $\begin{array}{c}47 \\
(+1)\end{array}$ & $\begin{array}{l}52 \\
(0)\end{array}$ & $\begin{array}{c}53 \\
(-1)\end{array}$ & $\begin{array}{l}47 \\
(0)\end{array}$ & $\begin{array}{c}0.78 \\
(0.67)\end{array}$ \\
\hline & Bellus 3D & $\begin{array}{c}45 \\
(+1)\end{array}$ & $\begin{array}{c}48 \\
(-2)\end{array}$ & $\begin{array}{c}45 \\
(-1)\end{array}$ & $\begin{array}{l}50 \\
(0)\end{array}$ & $\begin{array}{c}49 \\
(-2)\end{array}$ & $\begin{array}{c}45 \\
(-1)\end{array}$ & $\begin{array}{c}50 \\
(-2)\end{array}$ & $\begin{array}{l}54 \\
(0)\end{array}$ & $\begin{array}{l}47 \\
(0)\end{array}$ & $\begin{array}{c}1.00 \\
(0.87)\end{array}$ \\
\hline \multirow{4}{*}{$\begin{array}{l}\text { M4. } \\
\text { Full- } \\
\text { face } \\
\text { Length }\end{array}$} & Manual & 106 & 105 & 109 & 125 & 119 & 116 & 120 & 123 & 111 & \\
\hline & Artec Leo & $\begin{array}{c}106 \\
(0)\end{array}$ & $\begin{array}{l}107 \\
(+2)\end{array}$ & $\begin{array}{c}109 \\
(0)\end{array}$ & $\begin{array}{c}125 \\
(0)\end{array}$ & $\begin{array}{l}121 \\
(+2)\end{array}$ & $\begin{array}{l}115 \\
(-1)\end{array}$ & $\begin{array}{c}120 \\
(0)\end{array}$ & $\begin{array}{c}123 \\
(0)\end{array}$ & $\begin{array}{c}111 \\
(0)\end{array}$ & $\begin{array}{c}0.56 \\
(0.88)\end{array}$ \\
\hline & Structure & $\begin{array}{l}105 \\
(-1)\end{array}$ & $\begin{array}{l}108 \\
(+3)\end{array}$ & $\begin{array}{l}111 \\
(+2)\end{array}$ & $\begin{array}{c}125 \\
(0)\end{array}$ & $\begin{array}{c}119 \\
(0)\end{array}$ & $\begin{array}{l}115 \\
(-1)\end{array}$ & $\begin{array}{l}123 \\
(+3)\end{array}$ & $\begin{array}{l}124 \\
(+1)\end{array}$ & $\begin{array}{l}112 \\
(+1)\end{array}$ & $\begin{array}{c}1.33 \\
(1.12)\end{array}$ \\
\hline & Bellus 3D & $\begin{array}{l}104 \\
(-2)\end{array}$ & $\begin{array}{l}108 \\
(+3)\end{array}$ & $\begin{array}{l}108 \\
(-1)\end{array}$ & $\begin{array}{l}126 \\
(+1)\end{array}$ & $\begin{array}{l}120 \\
(+1)\end{array}$ & $\begin{array}{l}113 \\
(-3)\end{array}$ & $\begin{array}{c}120 \\
(0)\end{array}$ & $\begin{array}{l}122 \\
(-1)\end{array}$ & $\begin{array}{l}113 \\
(+2)\end{array}$ & $\begin{array}{c}1.56 \\
(1.01)\end{array}$ \\
\hline \multirow{4}{*}{$\begin{array}{l}\text { M5. } \\
\text { Half- } \\
\text { face } \\
\text { Length }\end{array}$} & Manual & 69 & 75 & 73 & 84 & 81 & 76 & 80 & 79 & 73 & \\
\hline & Artec Leo & $\begin{array}{l}69 \\
(0)\end{array}$ & $\begin{array}{c}76 \\
(+1)\end{array}$ & $\begin{array}{c}72 \\
(-1)\end{array}$ & $\begin{array}{c}85 \\
(+1)\end{array}$ & $\begin{array}{c}83 \\
(+2)\end{array}$ & $\begin{array}{l}76 \\
(0)\end{array}$ & $\begin{array}{c}78 \\
(-2)\end{array}$ & $\begin{array}{l}79 \\
(0)\end{array}$ & $\begin{array}{c}74 \\
(+1)\end{array}$ & $\begin{array}{c}0.89 \\
(0.78)\end{array}$ \\
\hline & Structure & $\begin{array}{l}69 \\
(0)\end{array}$ & $\begin{array}{c}74 \\
(-1)\end{array}$ & $\begin{array}{c}72 \\
(-1)\end{array}$ & $\begin{array}{c}86 \\
(+2)\end{array}$ & $\begin{array}{l}81 \\
(0)\end{array}$ & $\begin{array}{l}76 \\
(0)\end{array}$ & $\begin{array}{c}79 \\
(-1)\end{array}$ & $\begin{array}{c}80 \\
(+1)\end{array}$ & $\begin{array}{l}73 \\
(0)\end{array}$ & $\begin{array}{c}0.67 \\
(0.71)\end{array}$ \\
\hline & Bellus 3D & $\begin{array}{c}67 \\
(-2)\end{array}$ & $\begin{array}{c}72 \\
(-3)\end{array}$ & $\begin{array}{c}71 \\
(-2)\end{array}$ & $\begin{array}{c}87 \\
(+3)\end{array}$ & $\begin{array}{c}83 \\
(+2)\end{array}$ & $\begin{array}{c}75 \\
(-1)\end{array}$ & $\begin{array}{c}79 \\
(-1)\end{array}$ & $\begin{array}{c}76 \\
(-3)\end{array}$ & $\begin{array}{c}76 \\
(+3)\end{array}$ & $\begin{array}{c}2.22 \\
(0.83)\end{array}$ \\
\hline
\end{tabular}

P: Participant 


\section{Discussion and Conclusion}

\subsection{Overview}

In this study, 3D face scanning was performed using three scanners with different levels of prices and expertise, and the visual and anthropometric accuracy of the generated 3D models was compared. Textured and non-textured models were evaluated separately to provide comprehensive information according to the purpose of use. It was intended to present the characteristics of each scanner and the use for which it can be specialized.

Artec Leo, a high-cost scanner for professionals, was highly rated for both visual facial shape and dimensional accuracy, demonstrating the high reliability of 3D mesh implementation. Both textured and non-textured models are highly accurate and realistic overall, so they can be used in various ways, including product design and visual use. However, it may be suitable for industrial and academic uses that require high sophistication because of its high price and the need for skilled professionals for scanning and post-processing.

The mid-priced Structure Sensor obtained a 3D mesh shape with somewhat accurate dimensions, but it was sensitive to texture mapping and there was a high possibility of error and blurriness. Therefore, it may not be suitable for the purpose of accurately obtaining the texture of the face. Since landmarks become blurred and are difficult to see, it is necessary to mark landmarks larger or change the marking method to three-dimensional stickers. Although the anthropometric accuracy of Structure Sensor's nontextured model was relatively lower than that of Artec Leo, it still showed a medium level of dimensional and visual accuracy. Therefore, it could be used as a realistic alternative for product development or design use when considering price or level of expertise.

Bellus3D FaceApp, which was a free iOS application, had the advantage of being easy to access and able to acquire 3D faces in a short time. However, the anthropometric accuracy was low and the shape accuracy was poor, so it may not be suitable for accurate product development and design. Since the resolution and mapping accuracy of the textured models were high, there is a possibility to use it for visual use or to show design.

\subsection{Limitations and Future Research}

This study evaluated the visual and anthropometric accuracy of 3D models obtained with three scanners in the same environment. If the optimal environment for each scanner was validated, the results could be presented at the maximum quality level according to the scanners. In particular, there is a possibility that the scan quality of the Structure Sensor varies according to environmental factors such as illuminance and calibration, and mapping errors were continuously found for this study.

In this study, the anthropometric accuracy of 9 participants and the visual accuracy of 1 participant were evaluated. If a larger number of participants were evaluated, statistical significance and differences according to the facial characteristics of various participants could be examined. Even though the evaluation of visual accuracy was performed in a quantitative method, a mixed-method would enable a more detailed and specific analysis of which part influenced the expert's decision-making. Although this study was limited to portable type face scanners, future studies would analyze and validate more various face scanning technologies.

\subsection{Implications and Conclusion}

This study suggested a method for comprehensively evaluating face scanners at various levels and presented the level of utilization according to the accuracy and characteristics of each scanner. Information provided in the study will benefit researchers and industries who want to explore and utilize 3D face scanners for product development, research, and design purposes.

High visual and anthropometric accuracy does not necessarily increase use; it varies depending on the characteristics of each scanner. The selection of a scanner can be made according to the purpose of the user in consideration of comprehensive advantages, disadvantages, and circumstances such as budget, scanning environment, number of subjects, expert level, and required time. Rather than unconditionally using a high and accurate scanner, a balanced technology should be selected according to the purpose of data utilization. 


\section{References}

[1] Z. Zhuang, C. Shu, P. Xi, M. Bergman, and M. Joseph, "Head-and-Face Shape Variations of U.S. Civilian Workers," in Appl. Ergon., vol. 44, no. 5, pp. 775-784, 2013, https://doi.org/10.1016/J.APERGO.2013.01.008.

[2] M. Yokota, "Head and facial anthropometry of mixed-race US Army Male Soldiers for Military Design and Sizing: A Pilot Study," in Appl. Ergon., vol. 36, no. 3, pp. 379-383, 2005, https://doi.org/10.1016/J.APERGO.2005.01.009.

[3] Z. Zhuang, S. Benson, and D. Viscusi, "Digital 3-D Headforms with Facial Features Representative of the Current US Workforce," in Ergonomics, vol. 53, no. 5, pp. 661-671, 2010, https://doi.org/10.1080/00140130903581656.

[4] I. Amirav et al., "Design of Aerosol Face Masks for Children Using Computerized 3D Face Analysis," in J. Aerosol Med. Pulm. Drug Deliv., vol. 27, no. 4, pp. 272-278, 2014, https://doi.org/10.1089/jamp.2013.1069.

[5] W. Lee et al., "Analysis of the Facial Anthropometric Data of Korean Pilots for Oxygen Mask Design," in Proceedings of the Human Factors and Ergonomics Society, Sep. 2012, pp. 19271931, https://doi.org/10.1177/1071181312561282.

[6] W. Lee, H. Kim, D. Jung, S. Park, and H. You, "Ergonomic Design and Evaluation of a Pilot Oxygen Mask," in Proceedings of the Human Factors and Ergonomics Society, Sep. 2013, pp. 1673-1677, https://doi.org/10.1177/1541931213571371.

[7] H.N. Mai, J. Kim, Y.H. Choi, and D.H. Lee, "Accuracy of Portable Face-Scanning Devices for Obtaining Three-Dimensional Face Models: a Systematic Review and Meta-Analysis," in Int. J. Environ. Res. Public Health, vol. 18, no. 1, pp. 1-15, 2021, https://doi.org/10.3390/IJERPH18010094.

[8] C. L. Heike, K. Upson, E. Stuhaug, and S. M. Weinberg, "3D Digital Stereophotogrammetry: a Practical Guide to Facial Image Acquisition," in Head and Face Medicine, vol. 6, no. 1, pp. 1-11, 2010, https://doi.org/10.1186/1746-160X-6-18.

[9] L. Goto, W. Lee, J. F. M. Molenbroek, A. J. Cabo, and R. H. M. Goossens, "Traditional and 3D Scan Extracted Measurements of the Heads and Faces of Dutch Children," in Int. J. Ind. Ergon., vol. 73, p. 102828, 2019, https://doi.org/10.1016/J.ERGON.2019.102828.

[10]Y. Kang and S. Kim, "Development of Helmet Mold Design System Using 3D Anthropometric Analysis," in Int. J. Cloth. Sci. Technol., vol. 32, no. 3, pp. 446-456, 2020, https://doi.org/10.1108/IJCST-02-2019-0022.

[11]T. Y. Pang, T. S. T. Lo, T. Ellena, H. Mustafa, J. Babalija, and A. Subic, "Fit, Stability and Comfort Assessment of Custom-Fitted Bicycle Helmet Inner Liner Designs, Based on 3D Anthropometric Data," in Appl. Ergon., vol. 68, pp. 240-248, 2018, https://doi.org/10.1016/j.apergo.2017.12.002.

[12]B. Khambay, N. Nairn, A. Bell, J. Miller, A. Bowman, and A. F. Ayoub, "Validation and Reproducibility of a High-Resolution Three-Dimensional Facial Imaging System," in Br. J. Oral Maxillofac. Surg., vol. 46, no. 1, pp. 27-32, 2008, https://doi.org/10.1016/j.bjoms.2007.04.017.

[13] C. Boehnen and P. Flynn, "Accuracy of 3D Scanning Technologies in A Face Scanning Scenario," in Proceedings of International Conference on 3-D Digital Imaging and Modeling, 2005, pp. 310317, https://doi.org/10.1109/3DIM.2005.13.

[14]P. Amornvit and S. Sanohkan, "The Accuracy of Digital Face Scans Obtained from 3D Scanners: an In Vitro Study," in Int. J. Environ. Res. Public Heal. vol. 16, 5061, 2019, https://doi.org/10.3390/IJERPH16245061.

[15]Y. N. R. Gallardo, R. Salazar-Gamarra, L. Bohner, J. I. De Oliveira, L. L. Dib, and N. Sesma, "Evaluation of the 3D Error of 2 Face-Scanning Systems: an In Vitro Analysis," in J. Prosthet. Dent., 2021, https://doi.org/10.1016/J.PROSDENT.2021.06.049.

[16]W. Piedra-Cascón, M. J. Meyer, M. M. Methani, and M. Revilla-León, "Accuracy (Trueness and Precision) of a Dual-Structured Light Facial Scanner and Interexaminer Reliability," in J. Prosthet. Dent., vol. 124, no. 5, pp. 567-574, 2020, https://doi.org/10.1016/j.prosdent.2019.10.010.

[17] F. Pellitteri, L. Brucculeri, G. A. Spedicato, G. Siciliani, and L. Lombardo, "Comparison of the Accuracy of Digital Face Scans Obtained by Two Different Scanners: an In Vivo Study," in Angle Orthod., vol. 91, no. 5, pp. 641-649, 2021, https://doi.org/10.2319/092720-823.1.

[18] International Organization for Standardization, ISO 20685-1:2018 3-D Scanning Methodologies for Internationally Compatible Anthropometric Databases - Part 1: Evaluation Protocol for Body Dimensions Extracted from 3-D Body Scans. 2018. 